\title{
H1N1 influenza virus epitopes classified by monoclonal antibodies
}

\author{
CHUNYAN GUO $^{1 *}$, HAIXIANG ZHANG $^{1 *}$, XIN XIE $^{2}$, YANG LIU $^{1}$, LIJUN SUN $^{1}$, \\ HUIJIN LI ${ }^{3}$, PENGBO YU ${ }^{4}$, HANYU HU ${ }^{1}$, JINGYING SUN ${ }^{1}$, YUAN LI ${ }^{1}$, QING FENG ${ }^{1}$, \\ XIANGRONG ZHAO ${ }^{1}$, DAOYAN LIANG ${ }^{1}$, ZHEN WANG ${ }^{1}$ and $\mathrm{JUN} \mathrm{HU}^{1}$ \\ ${ }^{1}$ Central Laboratory, Shaanxi Provincial People's Hospital, Xi'an, Shaanxi 710068; ${ }^{2}$ Key Laboratory of Resource \\ Biology and Biotechnology in Western China, Ministry of Education, College of Life Sciences, Northwest \\ University, Xi'an, Shaanxi 710069; ${ }^{3}$ Shaanxi Key Laboratory of Ischemic Cardiovascular Disease, Institute \\ of Basic and Translational Medicine, Xi'an Medical University, Xi'an, Shaanxi 710021; ${ }^{4}$ Center of Shaanxi \\ Provincial Disease Control and Prevention, Institute of Viral Diseases, Xi'an, Shaanxi 710052, P.R. China
}

Received November 6, 2017; Accepted June 22, 2018

DOI: $10.3892 / e t m .2018 .6429$

\begin{abstract}
Epitopes serve an important role in influenza infection. It may be useful to screen universal influenza virus vaccines, analyzing the epitopes of multiple subtypes of the hemagglutinin (HA) protein. A total of 40 monoclonal antibodies (mAbs) previously obtained from flu virus HA antigens (development and characterization of $40 \mathrm{mAbs}$ generated using $\mathrm{H} 1 \mathrm{~N} 1$ influenza virus split vaccines were previously published) were used to detect and classify mAbs into distinct flu virus sub-categories using the ELISA method. Following this, the common continuous amino acid sequences were identified by multiple sequence alignment analysis with the GenBank database and DNAMAN software, for use in predicting the epitopes of the HA protein. Synthesized peptides of these common sequences were prepared, and used to verify and determine the predicted linear epitopes through localization and distribution analyses. With these methods, nine HA linear epitopes distributed among different strains of influenza virus were identified, which included three from influenza A, four from $2009 \mathrm{H} 1 \mathrm{~N} 1$ and seasonal influenza, and two from H1. The present study showed that considering a combination of the antigen-antibody reaction specificity, variation in the influenza virus HA protein and linear
\end{abstract}

Correspondence to: Professor Jun Hu, Central Laboratory, Shaanxi Provincial People's Hospital, 256 You Yi West Road, Xi'an, Shaanxi 710068, P.R. China

E-mail: hjj65622@163.com

${ }^{*}$ Contributed equally

Abbreviations: mAbs, monoclonal antibodies; HA, hemagglutinin; IR, inhibition rate; PDB, protein database

Key words: H1N1 influenza virus, monoclonal antibodies, epitope, classified epitopes may present a useful approach for designing effective multi-epitope vaccines. Furthermore, the study aimed to clarify the cause and pathogenic mechanism of influenza virus HA-induced flu, and presents a novel idea for identifying the epitopes of other pathogenic microorganisms.

\section{Introduction}

Infection by pathogenic microorganisms and viruses presents a significant threat to human life worldwide; their constant variation, evolution and spread render it difficult to prevent and control infection. HBV, one of the most infectious diseases worldwide, often varies due to the pressures of host immunity, natural selection and the use of antiviral agents. Such variations may cause changes in HBV pathogenicity, including the development of tolerance and immune escape, and have greatly hindered clinical diagnosis and treatment (1). A number of new HIV GAG subtypes have been reported due to its constant variation and accumulation (2). Continual variation in the influenza virus hemagglutinin (HA) antigen gene is the main cause of influenza outbreaks (3). This poses challenges for immunology, virology and immunopharmacology research, and for the development of vaccines against influenza and other pathogenic microorganisms.

Epitopes, also known as antigenic determinants, represent the material base of immunogen antigenicity, and is the part of an antigen recognized by the immune system. Epitopes can be classified as either conformational epitopes or linear epitopes, based on their structure and interaction with the paratope (4). The linear epitope is a section of the continual amino acid sequence of the antigen, and its interaction with the paratope predominantly depends on its primary structure. Variations in any area of the linear epitopes may lead to structural changes, a reduced antibody binding ability, and the ability to escape recognition by existing antibodies and vaccines (5).

Different subtypes of a pathogen may have a variety of antigens; thus, it is challenging to distinguish the subtype of pathogenic microorganisms, to establish immunodetection technologies, and to clarify the mechanisms of disease spread. 
Consequently, epitope prediction and utilization are of value in differential diagnosis, the prediction of variation trends, determining the mechanisms of pathogenic microorganism infection, and in the design of multi-epitope vaccines (6).

Recently, several methods of epitope prediction have been in use, the majority of which are limited to one antigen, although they still provide a satisfactory predictive capacity (7-9). X-ray diffraction requires more time and energy to identify epitope structures. To elucidate the biological profile of the epitope, multiple factors should be considered, including its location on the surface of the antigen, the flexibility, and the accessibility, although it showed a growing acceptance among this field (10-14). In addition to $\alpha$-helices and $\beta$-pleated sheets, glycosylation sites are also important for prediction (15). However, the predictive accuracy of these methods is just $\sim 60 \%$ (16). Larger protein libraries are required for phage display technology, and certain peptides have strong hydrophobicity, which influences their structure on the surface of phages. Furthermore, the predictions obtained via this method still require further verification (17). Thus, a single optimal approach is required, which is capable of predicting the epitope sequences of microorganisms comprehensively and in one pass, establishing a biological profile with the characteristics and functions of the epitopes, and modeling the behavior of these epitopes during changes to virus antigenicity. This will have an important and direct role in the design of biologically active drugs, research into pathogenic mechanisms, and the prediction of variation in certain pathogenic microorganisms.

Monoclonal antibodies (mAbs) are a subset of antibodies generated by identical immune cells with a strong monovalent affinity, in that they bind to the same epitope, with high specificity and sensitivity, and define the structure and character of epitopes (18). Such specificity can also be used as a tool to analyze the epitopes of viruses and their subtypes, provide information on the main functions of the epitopes and on genetic variations involved in changes to the epitopes, and assist research into epitope variation and improvements in vaccine design $(19,20)$.

In the present study, mAbs from 40 previously developed anti-H1N1 influenza virus HA split vaccines had been developed and characterized (21), which were used as experimental tools to predict the epitopes of influenza virus HA proteins, after which their distribution and expression were investigated using synthesized peptides. The present study aimed to illuminate the association between variation in the influenza virus and its immunogenicity, and to develop a useful method for predicting the variable epitopes of other pathogenic microorganisms. In the present study, we just preliminary report a new method for predicting the variability epitope of influenza virus. Next, we will carry out biological functional studies on predicted different epitopes one by one, which can help us to develop epitope vaccines of influenza virus, further contribute to the diagnosis and prevention of influenza virus.

\section{Materials and methods}

Antigens. H1N1 influenza virus split vaccine (2009; SFDA Approval no.: S20090015) was obtained from Hualan Biological Bacterin Co.,Ltd.,(Henan, China); seasonal A1 and A3 influenza [2009; Veterinary Drug Production Approval no.: 150132145], and H9N2 (SD696) strains were purchased from Qingdao Yebio Bioengineering Co., Ltd., (Shandong, China).

Antibodies. mAbs against the anti-H1N1 A influenza virus HA protein were prepared in our laboratory, and HRP-conjugated goat anti-mouse antibodies were provided by Beijing Zhongshan Golden Bridge Biotechnology Co., Ltd., (Beijing, China).

HA protein synthetic peptides. Part of the continuous amino acid sequence of influenza virus HA was determined using DNAMAN software, and peptides were synthesized by ChinaPeptides Co., Ltd., (Shanghai, China).

ELISA analysis and classification. Indirect ELISA analyses were performed using the following: Hybridoma culture supernatant; H1N1 influenza virus split vaccine (2009); seasonal influenza viruses A1 and A3; and avian influenza viruses H5N1 and H9N2. Briefly, the 96-well plate was pre-coated with $100 \mu \mathrm{l}$ of each vaccine $(2-5 \mu \mathrm{g} / \mathrm{ml})$. After washing three times with PBST (including $8 \mathrm{~g}$ of $\mathrm{NaCl}, 0.2 \mathrm{~g}$ of $\mathrm{KCl}, 1.44 \mathrm{~g}$ of $\mathrm{Na}_{2} \mathrm{HPO}_{4}, 0.24 \mathrm{~g}$ of $\mathrm{KH}_{2} \mathrm{PO}_{4}, 2 \mathrm{ml}$ of Tween-20, $\mathrm{pH} 7.2$, volume adjusted to $1 \mathrm{~L}$ with additional distilled $\mathrm{H}_{2} \mathrm{O}$ ), the plates were blocked with $200 \mu \mathrm{l}$ skim milk (dilution, 1:20) and incubated for $1 \mathrm{~h}$ at $37^{\circ} \mathrm{C}$. Subsequently, $100 \mu \mathrm{l} /$ well supernatant aspirated from the hybridoma cell cultures for $40 \mathrm{mAbs}$ was added, including the supernatant of SP2/0 as a negative control, which was incubated for $1 \mathrm{~h}$ at $37^{\circ} \mathrm{C}$. After washing a further three times, the concentration (dilution, 1:2,500) of the HRP-labeled goat-anti-mouse IgG mAb (100 $\mu \mathrm{l} /$ well) was added and incubated for $1 \mathrm{~h}$ at $37^{\circ} \mathrm{C}$. Next, $100 \mu \mathrm{l}$ TMB- $\mathrm{H}_{2} \mathrm{O}_{2}$ chromogenic solution was added to each well and incubated for $10 \mathrm{~min}$ at $37^{\circ} \mathrm{C}$ in the dark, and terminated with $\mathrm{H}_{2} \mathrm{SO}_{4}$ solution ( $2 \mathrm{M}, 50 \mu \mathrm{l} /$ well). Finally, the proportion of bound antibodies, which is correlated with the color intensity, was measured with an ELISA reader via absorbance at $450 \mathrm{~nm}$. The ratio of each test sample $\left(\mathrm{OD}_{450}\right.$ : Control $\left.\mathrm{OD}_{450}\right)$ was calculated. Samples with a ratio of $\geq 2.1$ were classified as exhibiting a positive reaction. Considering each test sample reaction with the five subtypes of the influenza virus, the antibodies were categorized into different groups.

Epitopes of influenza A virus $H A$ protein prediction. In the NCBI database (http://www.ncbi.nlm. nih.gov/genomes/FLU/FLU.html), the amino acid sequences of various influenza virus subtypes were accessed and downloaded with their GenBank IDs (Table I). Consequently, a multiple sequence alignment analysis was performed using DNAMAN software, following which the common continuous amino acid sequence (5-7 aa) between the antigens of the different groups were defined, and used to predict the epitopes of influenza A virus HA proteins. Overall, 27 candidate epitope fragments were selected, and complementary peptides were synthesized, each with a $>85 \%$ purity as measured by HPLC and MS methods; these peptides were stored as freeze-dried powders at $-20^{\circ} \mathrm{C}$.

Localization of predicted epitopes with anti-influenza virus $H A$ mAbs. To investigate the positions of the predicted epitopes of influenza A virus HA, 27 candidate-epitope peptides 
Table I. Information about the amino acid sequences of subtype influenza virus.

\begin{tabular}{llr}
\hline Name of antigens & Source of HA amino acid sequence & GenBank ID \\
\hline 2009 H1N1-HA & (A/reassortant/NYMCX-179A (California/07/2009xNYMC X-157)(H1N1)) & ACR47014.1 \\
H3N2-HA & Influenza A virus (A/Victoria/210/2009(H3N2)) & CY121077.1 \\
Seasonal H1N1-HA & Influenza A virus (A/Brisbane/59/2007(H1N1)) & CY163864.1 \\
H5N1-HA & Influenza A virus (A/Goose/Guangdong/1/96(H5N1)) & AF144305.1 \\
H9N2-HA & Influenza A virus (A/chicken/Shandong/6/96(H9N2)) & AAY52514.1
\end{tabular}

HA, hemagglutinin.

Table II. mAb cross-reactivity with various subtypes of influenza virus.

mAb group

No. of cell lines

Common antigens of influenza virus

(2009 H1N1 and seasonal A1, A3 and avian influenza H5N1 and H9N2)

Common antigens of $2009 \mathrm{H} 1 \mathrm{~N} 1$ influenza virus and seasonal influenza virus

(2009 H1N1 and seasonal A1, A3)

Specific H1 subtype

6

(2009 H1N1and seasonal A1)

Total

40

$\mathrm{mAB}$, monoclonal antibody.

were used and screened using mAbs against influenza virus HA. The process was as follows: The synthesized peptides were mixed with $40 \mathrm{HA} \mathrm{mAbs}$, and incubated for $1 \mathrm{~h}$ at $37^{\circ} \mathrm{C}$. A total of $100 \mu \mathrm{l}$ mixed reagent was placed into each well of an ELISA plate pre-coated with H1N1 influenza virus HA antigens $(2 \mu \mathrm{g} / \mathrm{ml})$, according to standard ELISA protocols. After a $1 \mathrm{~h}$ incubation and three washes, the goat anti-mouse antibodies (dilution, 1:2,500) were added, and the steps of a conventional ELISA were performed. The $\mathrm{OD}_{450}$ values for all wells were calculated from TMB coloration and an inhibition rate (IR) was calculated. The formula used to calculate the IR was as follows: IR $=\left(\mathrm{OD}_{\mathrm{CTL}}-\mathrm{OD}_{\mathrm{TEST}}\right) / \mathrm{OD}_{\mathrm{CTL}}$. Correlations between the antigens and the antibody binding sites were defined according to the following criteria: No correlation (IR $\leq 0.4)$; correlation $(0.4 \leq \mathrm{IR} \leq 0.8)$; and strong correlation (IR $\geq 0.8$ ).

Distribution of predicted epitopes in the HA crystal structure. The PyMOL Molecular Graphics System (http://www.PyMOL. org) and Protein Database (PDB) were used to analyze the distribution of predicted epitopes in the HA crystal structure. Peptides recognized by $m$ Abs against influenza virus HA proteins in the ELISA experiments were selected and analyzed. First, the PDB database was used to search for and generate a model of the HA protein X-ray crystal structure by referring to the $3 \mathrm{LZG}$ structure, which was produced from the A/California/04/2009 H1N1 virus HA and had a similar structure to that of the antigen in the present study. Secondly, the selected peptides' distributions were determined using PyMOL software according to the manufacturer's protocol.

\section{Results}

Specificity and cross reactivity of $m A b s$. ELISA reactions between 40 influenza virus HA antigen mAbs and five different influenza virus subtype vaccines were evaluated using the $\mathrm{OD}_{450}$ ratio, and classified as positive $\left(\mathrm{OD}_{450} \geq 2.1\right)$ or negative $\left(\mathrm{OD}_{450}<2.1\right)$ reactions. According to the cross-ELISA results, all the assessed influenza virus HA antigens can be classified into three groups. Approximately half (20/40) were recognized by all five antigens, $\sim 35 \%$ (14/40) were recognized by the antigens of $2009 \mathrm{H} 1 \mathrm{~N} 1$ virus $\mathrm{A}$, or seasonal influenza virus $\mathrm{A} 1$ and $\mathrm{A} 3$, and $6 \mathrm{mAbs}$ only reacted with the antigens of H1N1 virus A and seasonal A1 (Table II).

Detection of conserved peptides in influenza virus A HA. Twenty seven common continuous amino acid sequences of influenza HA antigens detected through multiple sequence alignment analysis of the three groups using DNAMAN software (Table III). There were 9 peptides located in the conserved sequences of vaccines in group 1,7 peptides in the conserved sequences of group 2, and 11 in group 3 (Table III).

Locations of predicted epitopes determined using anti-influenza virus HA mAbs. The ELISA results demonstrated that 9/27 peptides were recognized by $13 / 40 \mathrm{mAbs}$, considering their IRs calculated with $\mathrm{OD}_{450}$ values (Figs. 1-3). In group 1, 5 mAbs were identified by 3 peptides, designated peptides 1, 2 and 9 (Fig. 1); in group 2, 6 mAbs reacted with 4 peptides (peptides 10, 11, 15 and 16; Fig. 2); and 2 mAbs in group 3 were identified by 2 peptides (peptides 17 and 27; Fig. 3 ). 
Table III. Peptide fragments in influenza virus HA identified subtype influenza virus mAbs.

\begin{tabular}{|c|c|c|}
\hline $\begin{array}{l}\text { Groups and } \\
\text { peptides no. }\end{array}$ & Sequence of peptides & Position \\
\hline \multicolumn{3}{|l|}{ Group 1: $(9)^{\mathrm{a}}$} \\
\hline Peptide & LVLWGIHHP & 191aa-199aa \\
\hline Peptide 2 & LPFQNI & 307aa-312aa \\
\hline Peptide 3 & LATGLRN & 331aa-337aa \\
\hline Peptide 4 & RGLFGAIAGFIEGGW & 344aa-358aa \\
\hline Peptide 5 & GWYGYHH & 364aa-370aа \\
\hline Peptide 6 & STQNAID & 384aa-390aa \\
\hline Peptide 7 & YNAELLVL & 438aa-445aа \\
\hline Peptide 8 & ENERTLD & 447aa-453aa \\
\hline Peptide 9 & WSYIVE & 93aа-98aa \\
\hline \multicolumn{3}{|l|}{ Group 2: $(7)^{b}$} \\
\hline Peptide 10 & DTLCIGYHANNSTDT & $17 \mathrm{aa}-32 \mathrm{aa}$ \\
\hline Peptide 11 & MNYYWTLVEPGD & 244aa-255aa \\
\hline Peptide 12 & ATGNLVVPR & 261aa-269aа \\
\hline Peptide 13 & GYAADLKSTQNAIDEI & 377aa-392aa \\
\hline Peptide 14 & EIGNGCF & 476аa-482aa \\
\hline Peptide 15 & FYHKCDNT & 484aa-491aa \\
\hline Peptide 16 & SVKNGTYD & 495aa-502aa \\
\hline \multicolumn{3}{|l|}{ Group 3: $(11)^{\mathrm{c}}$} \\
\hline Peptide 17 & KAILVVLLYTFA & $2 \mathrm{aa}-13 \mathrm{aa}$ \\
\hline Peptide 18 & SVNLLEDK & 46aа-53aа \\
\hline Peptide 19 & KLRGVAPLHLGK & 60aa-71aa \\
\hline Peptide 20 & ESLSTASS & $85 a a-92 a a$ \\
\hline Peptide 21 & TSSSDNGT & 99aa-106aа \\
\hline Peptide 22 & PNHDSNKGVTA & 141aa-151aa \\
\hline Peptide 23 & PHAGAKSFYKNLI & 154aa-166aa \\
\hline Peptide 24 & KLSKSYINDKGKEV & 177aa-190aа \\
\hline Peptide 25 & GSSRYSKKFKPE & 219aa-230aа \\
\hline Peptide 26 & RYAFAMERNAGSG & 269aa-281aa \\
\hline Peptide 27 & VVSLGAISF & 544aa-552aa \\
\hline
\end{tabular}

a2009 H1N1 and seasonal A1, A3 and avian influenza H5N1 and H9N2; '2009 H1N1 and seasonal influenza virus A1, A3; 2009 H1N1and seasonal A1. mAB, monoclonal antibody; HA, HA, hemagglutinin.

Distribution of predicted epitopes in the HA crystal structure. After the predicted epitopes were located, three peptides (including 93-WSYIVE-98, 191-LVLWGIHHP-199 and 307-LPFQNI-312), located in the continuous conserved amino acid sequences in all five HA antigens, were chosen for distribution analysis. PyMOL software analysis identified the three peptides sequences in the HA crystal structure, and predicted their location in the 3D structure of HA (Fig. 4).

\section{Discussion}

Variability in the HA proteins of the influenza virus impacts on the suitability and efficacy of existing vaccines. Developing universal vaccines effective against various subtypes of

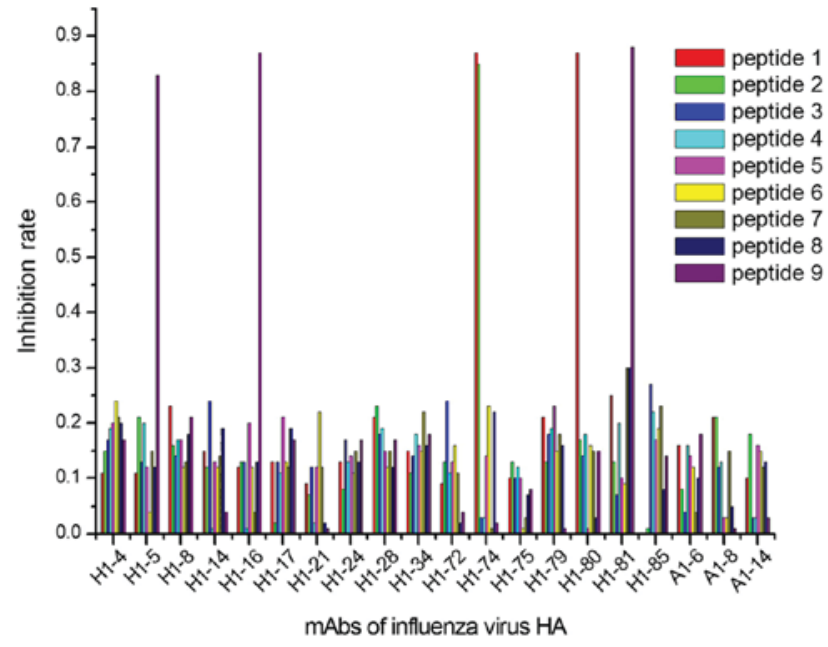

Figure 1. Positioning results of $\mathrm{mAbs}$ against common antigens of influenza virus $\mathrm{A}$ in conserved areas of the influenza virus HA protein sequence. In total, 5 mAbs (H1-5, H1-16, H1-74, H1-80 and H1-81) showed a strong interaction ( $I R \geq 0.8$ ) with 3 epitopes (peptides 1,2 , and 9). mAbs, monoclonal antibodies; HA, hemagglutinin.

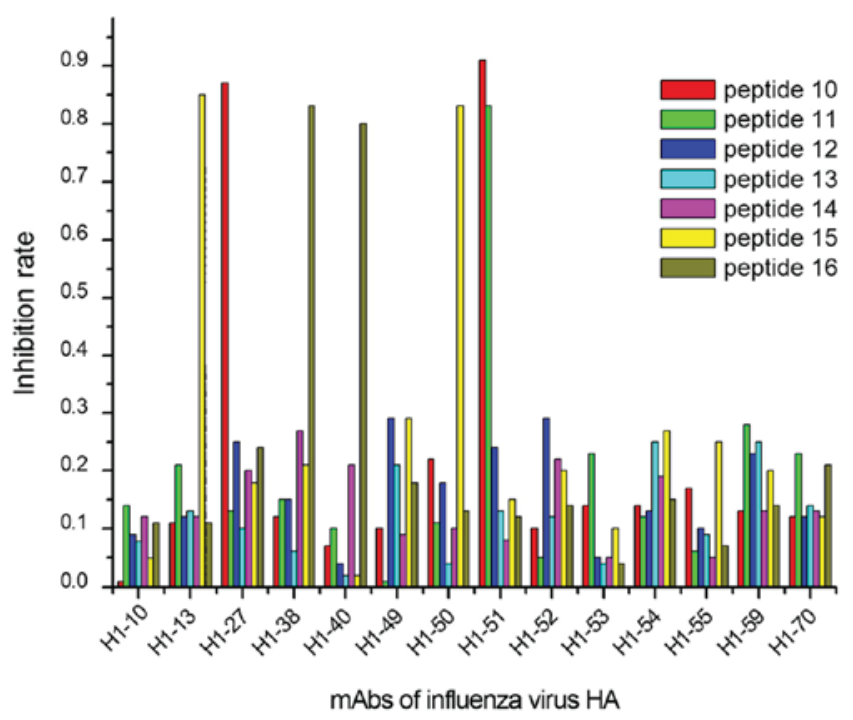

Figure 2. Positioning results of $\mathrm{mAb}$ against common antigens of the influenza A virus H1N1 and seasonal influenza virus in conserved areas of the influenza virus $\mathrm{H} 1 \mathrm{~N} 1+\mathrm{A} 1+\mathrm{A} 3$ and HA sequences. A total of 6 mAbs (H1-13, H1-27, H1-38, H1-40, H1-50 and H1-51) showed a strong interaction (IR $\geq 0.8$ ) with 4 epitopes (peptides 10,11, 15 and 16). mAbs, monoclonal antibodies; HA, hemagglutinin.

influenza is the primary approach for controlling the spread of infection (22). As epitopes are a key feature of viruses, several strategies have been successfully applied in the design and development of 'epitope-focused' vaccines $(23,24)$, which demonstrate advantages such as high specificity, fewer side effects, simple preparation, and easy storage and transportation $(25,26)$. These rapid and accurate strategies have become the foundation for the development of influenza virus vaccines, as well as supporting clinical diagnosis and treatment.

In the present study, we predicted the epitopes of multiple subtypes of the influenza virus HA protein using 40 previously developed mAbs, and extracted the common continuous amino acid sequences as linear epitopes. Following this, we 


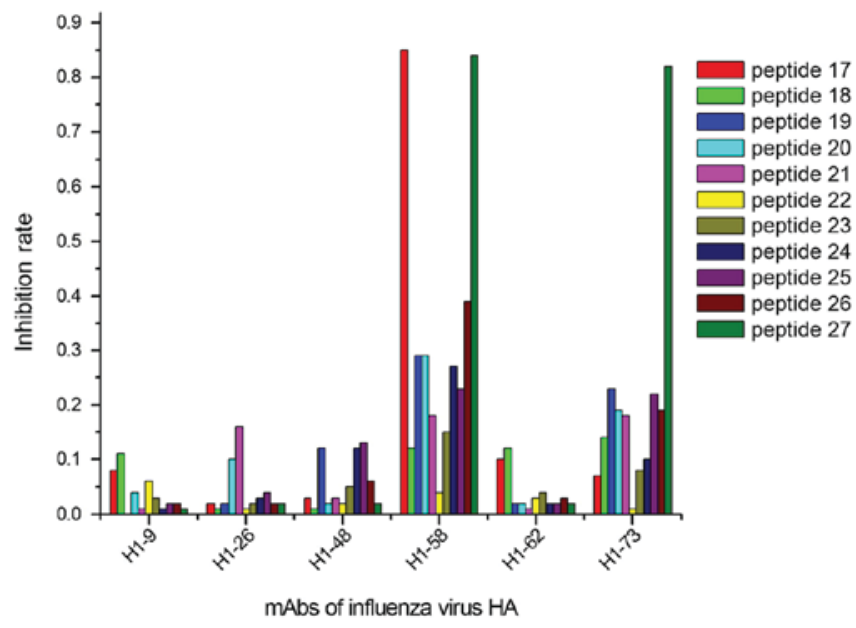

Figure 3. Positioning results of mAbs allowed the identification of the $\mathrm{H} 1$ subtype influenza virus HA. Additionally, 2 mAbs (H1-58 and H1-73) showed a strong interaction ( $I R \geq 0.8$ ) with 2 epitopes (peptides 17 and 27). mAbs, monoclonal antibodies; HA, hemagglutinin.

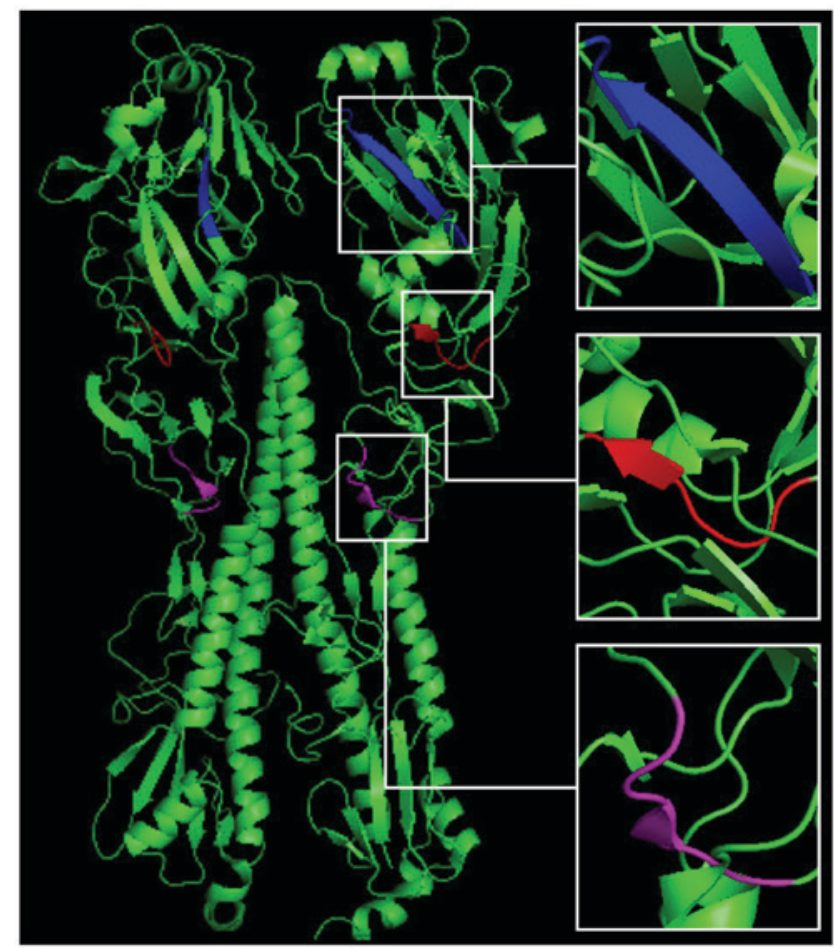

Figure 4. Distribution of three peptides in the HA crystal structure. We searched for a crystal structure of the H1N1 influenza A virus in the PDB, and used $3 \mathrm{LZG}$ as a reference structure. PyMOL software was used to determine the distribution of three peptides in the 3D crystal structure of HA, from which we noted that the WSYIVE peptide (red) and the LPFQNI peptide (purple) are located on the random coil domain, whereas the LVLWGIHHP peptide (blue) is situated within the $\beta$-sheet structure. HA, hemagglutinin.

determined the localization and distribution with candidate peptide analysis, to verify and confirm 9 linear epitopes of the HA protein. For five common subtypes of the influenza virus, 3 epitopes (peptides 1,2 and 9) showed a strong association with multiple influenza viruses. Additionally, three epitopes are known to overlap with three neutralizing epitopes, HA183 $\sim 195$, HA127 133 and HA92 105, of the H3 subtype influenza virus HA protein, as reported by Li et al (27). It is also suspected that the three peptides 1-LVLWGIHHP, 2-LPFQNI and 9-WSYIVE may stimulate organisms to produce neutralizing antibodies and promote immunogenicity, which may benefit the development of universal influenza vaccines.

In the second group, which included the 2009 influenza A virus $\mathrm{H} 1 \mathrm{~N} 1$, and the seasonal influenza A1 and A3 virus, four linear epitopes were identified. The epitopes in the conserved sequences of this group were immunodominant epitopes, capable of stimulating organisms to produce a high volume of antibodies in response. Therefore, there were more chances of mixed infection of three of them presently (28). In the third group, two linear epitopes were predicted, which are the main markers used to distinguish between the HA proteins of $\mathrm{H} 1$ and other subtypes. Our results suggested that only $15 \%(6 / 40)$ of the antibodies are produced by organisms when stimulated by epitopes in group 3, due to there being fewer common epitopes between these two subtypes of the influenza virus. To an extent, this observation may also explain the significant difference between the H1N1 influenza virus subtypes in terms of the infection frequency, pathogenicity and infection scale, among other variables (29).

As identified in ELISA experiments, 13/40 anti-influenza virus HA antigens were positioned at 9 epitopes. In group 1, we synthesized 9 peptides after analyzing the common sequences of the human and avian influenza viruses using DNAMAN software and $20 \mathrm{mAbs}$ against epitopes common to both viruses; we positioned 5 antigens to 3 epitopes. Li et al (27), used an $E$. coli model to demonstrate that rabbits and mice are immune to recombinant multi-epitope peptides specific to three neutralizing epitopes, HA183 195, HA127 133 and HA92 105, from the H3 subtype of influenza virus HA, and neutralizing antibodies with high titer were produced. This indicated that, in the first group, among peptides able to identify multiple subtypes of the influenza virus, 1-LVLWGIHHP and 9-WSYIVE could potentially stimulate organisms to produce neutralizing antibodies, which would benefit the development of universal influenza vaccines. In the second group, we designed 7 peptides complementary to the antigen-conserved areas of $14 \mathrm{mAbs}$. We positioned 4 epitopes to $6 \mathrm{mAbs}$. Epitopes in the conserved areas of the 2009 influenza A virus H1N1, and the seasonal influenza A1 and A3 viruses were immunodominant, and stimulated organisms to produce an abundance of antibodies in response. In the third group, 2 antigens were positioned to 2 epitopes. Epitopes corresponding with these antibodies are the primary markers used to distinguish between the HA proteins of $\mathrm{H} 1$ and other subtypes.

Influenza virus HA proteins include 562-566 amino acids and consist of a HA1 spherical head (319-328aa) and a HA2 bacilliform stalk (221-222aa). HA1 includes 8 anti-parallel $\beta$-laminated structures, including a receptor-binding domain (RBD) and 5 antigenic determinants: A, B, C, D and E (30). The RBD domain is composed of a helix at site 190, and of rings at sites 130 and 220; one of the predicted epitopes, verified by peptide 191-LVLWGIHHP-199, was located near this domain (Fig. 4), indicating that the current method was effective and reliable, and could be used to investigate the mechanisms underlying the spread of influenza, its genetic variation, and in the development of epitope-specific vaccines.

To predict the epitopes of influenza HA proteins, we used the antigen-antibody reaction method. Multiple reactivity 
modes were observed, including the one-to-one mode, the one-to-many mode (H1-74 reacted with peptides 1 and 2; H1-51 reacted with peptides 10 and 11; H1-58 reacted with peptides 17 and 27), and the unresponsive mode. Two findings were notable: First, two peptides that react with the same antibody were close to the 3D structure of HA, and formed a conformational epitope, although they were separated by a long sequence in the primary structure; second, $40 \mathrm{mAbs}$ were obtained using the split influenza virus vaccine, and these immunogens can induce organisms to produce the same antibodies as those induced by natural pathogens. Synthesized peptides, for which the design and utilization were based on the primary sequence of the protein, were used for linear epitope prediction and identification.

These short peptides can be also used as good immunogens to research different subtypes of influenza virus epitope vaccines. Li et al (31) applied short-peptide immunization to the mice directly, and screened the prepared mAbs. In order to enhance immunogenicity, connection of polypeptides and macromolecular protein can also be used. Gong et al (32) coupled the short peptides P1 P6 of the chemically synthesized influenza virus H3N2 sequence with the Keyhole Limpet Hemocyanin (KLH) carrier protein in order to increase the immunogenicity of the polypeptide, and induced a strong humoral immune response. We have previously linked 9 different polypeptides with KLH one by one, obtaining high titer and high affinity polyclonal antibodies after immunizing mice. Polyclonal antibodies were then tested for their neutralizing activity and cross-reactivity with human tissues. These experiments are underway.

In conclusion, the present study identified 9 linear epitopes of the influenza HA protein via traditional $\mathrm{mAb}$ and antigen interaction analysis, and verified these using ELISA and 3D structure location analyses with synthesized peptides. The results provide a novel, effective and reliable method for investigating the mechanisms underlying the spread and variation of influenza virus and other pathogenic microorganisms, in addition to improving the development of epitope-focused vaccines.

\section{Acknowledgements}

Not applicable.

\section{Funding}

This work was supported by Natural Science Basic Research Program of Shaanxi Province (grant no. 2016JM8065); The National Key Research and Development Program of China (grant no. 2016YFD0500700); The Natural Science Foundation of China (grant no. 81202373).

\section{Availability of data and materials}

All data generated or analyzed during this study are included in this published article.

\section{Authors' contributions}

CG, HZ, XX and JH conceived and designed the experiments; CG, HL, PY, HH, JS, YL, QF, XZ, DL and ZW performed the experiments; $\mathrm{CG}, \mathrm{HZ}$ and $\mathrm{JH}$ analyzed the data; $\mathrm{CG}, \mathrm{HZ}, \mathrm{YL}$,
PY and LS made data interpretation and critical manuscript revisions; $\mathrm{CG}$ and $\mathrm{HZ}$ wrote the manuscript.

\section{Ethics approval and consent to participate}

Not applicable.

\section{Patient consent for publication}

Not applicable.

\section{Competing interests}

The authors declare that they have no competing interests.

\section{References}

1. Cao L, Zhu F and Zeng CL: To explore the clinical value of the Hepatitis B virus mutation detection by the gene chip technology testing. Chin J Lab Diagn 19: 1301-1303, 2015.

2. Tedbury PR, Mercredi PY, Gaines CR, Summers MF and Freed EO: Elucidating the mechanism by which compensatory mutations rescue an HIV-1 matrix mutant defective for gag membrane targeting and envelope glycoprotein incorporation. J Mol Biol 427: 1413-1427, 2015.

3. Nishioka R, Satomura A, Yamada J, Kuroda K and Ueda M: Rapid preparation of mutated influenza Hemagglutinins for Influenza virus pandemic prevention. AMB Express 6: 8, 2016.

4. Huang $\mathbf{J}$ and Honda W: CED: A conformational epitope database. BMC Immunol 7: 7, 2016.

5. Huang X,Lu D, Ji G, Sun Y, Ma L, Chen Z, Zhang L, Huang J and Yu L: Hepatitis B virus (HBV) vaccine-induced escape mutants of HBV S gene among children from Qidong area, China. Virus Res 99: 63-68, 2004.

6. Zerbe K, Moehle K and Robinson JA: Protein epitope mimetics: From new antibiotics to supramolecular synthetic vaccines. Acc Chem Res 50: 1323-1331, 2017.

7. Khairy WOA, Wang L, Tian X, Ye J, Qian K, Shao H and Qin A: Identification of a novel linear B-cell epitope in the p27 of Avian leukosis virus. Virus Res 238: 253-257, 2017.

8. Nezafat N, Eslami M, Negahdaripour M, Rahbar MR and Ghasemi Y: Designing an efficient multi-epitope oral vaccine against Helicobacter pylori using immunoinformatics and structural vaccinology approaches. Mol Biosyst 13: 699-713, 2017.

9. Wang H, Liu R, Zhang W, Sun L, Ning Z, Ji F, Cui J and Zhang G: Identification of epitopes on nonstructural protein 7 of porcine reproductive and respiratory syndrome viru tecohnlogy. s recognized by monoclonal antibodies using phage-display. Virus Genes 53: 623-635, 2017.

10. De Groot AS, Sbai H, Aubin CS, McMurry J and Martin W: Immuno-informatics: Mining Genomes for vaccine components. Immunol Cell Biol 80: 255-269, 2002.

11. El-Manzalawy Y and Honavar V: Recent advances in B-cell epitope prediction methods. Immunome Res 6 (Suppl 2): S2, 2010.

12. Liang L, Huang P, Wen M, Ni H, Tan S, Zhang Y and Chen Q: Epitope peptides of influenza H3N2 virus neuraminidase gene designed by immunoinformatics. Acta Biochim Biophys Sin (Shanghai) 44: 113-118, 2012.

13. Igarashi M, Ito K, Yoshida R, Tomabechi D, Kida H and Takada A: Predicting the antigenic structure of the pandemic (H1N1) 2009 influenza virus hemagglutinin. PLos One 5: e8553, 2010.

14. Pan W, Chen DS, Lu YJ, Sun FF, Xu HW, Zhang YW, Yan C, Fu LL, Zheng KY and Tang RX: Bioinformatic prediction of the epitopes of Echinococcus granulosus antigen 5. Biomed Rep 6: 181-187, 2017.

15. Chen W, Zhong Y, Qin Y, Sun S and Li Z: The evolutionary pattern of glycosylation sites in influenza virus (H5N1) hemagglutinin and neuraminidase. PLoS One 7: e49224, 2012.

16. Huang YX, Bao YL and Li YX: Advances in immunological information methods for prediction of antigenic epitopes. Chin J Immunol 24: 857-860, 2008.

17. Xiao C, Liu Y, Jiang Y, Magoffin DE, Guo H, Xuan H, Wang G, Wang LF and Tu C: Monoclonal antibodies against the nucleocapsid proteins of henipaviruses: Production, epitope mapping and application in immunohistochemistry. Arch Virol 153: 273-281, 2008. 
18. O'Brien CM, Chy HS, Zhou Q, Blumenfeld S, Lambshead JW, Liu X, Kie J, Capaldo BD, Chung TL, Adams TE, et al: New monoclonal antibodies to defined cell surface proteins on human pluripotent stem cells. Stem Cells 35: 626-640, 2017.

19. Jia XY, Yu JT, Hu SY, Li JN, Wang M, Wang C, Chen M, Cui $\mathrm{Z}$ and Zhao MH: Antibodies against linear epitopes on Goodpasture autoantigen in patients with anti-neutrophil cytoplasmic antibody-associated vasculitis. Clin Rheumatol 26, 2017.

20. Jones ML, Legge FS, Lebani K, Mahler SM, Young PR, Watterson D, Treutlein HR and Zeng J: Computational identification of antibody epitopes on the dengue virus NS1 protein. Molecules 22: E607, 2017.

21. Guo CY, Tang YG, Qi ZL, Liu Y, Zhao XR, Huo XP, Li Y, Feng Q, Zhao PH, Wang X, et al: Development and characterization of a panel of cross-reactive monoclonal antibodies generated using H1N1 influenza virus. Immunobiology 8: 941-946, 2015.

22. Jegaskanda S, Vanderven HA, Wheatley AK and Kent SJ: Fc or not Fc; that is the question: Antibody Fc-receptor interactions are key to universal influenza vaccine design. Hum Vaccin Immunother 13: 1-9, 2017.

23. Correia BE, Bates JT, Loomis RJ, Baneyx G, Carrico C, Jardine JG, Rupert P, Correnti C, Kalyuzhniy O, Vittal V, et al: Proof of principle for epitope-focused vaccine design. Nature 507: 201-206, 2014

24. McBurney SP, Sunshine JE, Gabriel S, Huynh JP, Sutton WF, Fuller DH, Haigwood NL and Messer WB: Evaluation of protection induced by a dengue virus serotype 2 envelope domain III protein scaffold/DNA vaccine in non-human primates. Vaccine 34: 3500-3507, 2016

25. Cao Y, Li D, Fu Y, Bai Q, Chen Y, Bai X, Jing Z, Sun P, Bao H, Li P, et al: Rational design and efficacy of a multi-epitope recombinant protein vaccine against foot-and-mouth disease virus serotype A in pigs. Antiviral Res 140: 133-141, 2017.
26. Baratelli M, Pedersen LE, Trebbien R, Larsen LE, Jungersen G, Blanco E, Nielsen $J$ and Montoya M: Identification of cross-reacting T-cell epitopes in structural and non-structural proteins of swine and pandemic H1N1 influenza A virus strains in pigs. J Gen Virol 98: 895-899, 2017.

27. Li H, Ding J and Chen YH: Recombinant protein comprising multi-neutralizing epitopes induced high titer of antibodies against influenza A virus. Immunobiology 207: 305-313, 2003.

28. Myers CA, Kasper MR, Yasuda CY, Savuth C, Spiro DJ, Halpin R, Faix DJ, Coon R, Putnam SD, Wierzba TF and Blair PJ: Dual infection of novel influenza viruses $\mathrm{A} / \mathrm{H} 1 \mathrm{~N} 1$ and $\mathrm{A} / \mathrm{H} 3 \mathrm{~N} 2$ in a cluster of Cambodian patients. Am J Trop Med Hyg 85: 961-963, 2011.

29. Kilbourne ED: Influenza pandemics of the 20th century. Emerg Infect Dis 12: 9-14, 2006.

30. Han T and Marasco WA: Structural basis of influenza virus neutralization. Ann N Y Acad Sci 1217: 178-190, 2011.

31. Li Y, Hu HY, Qi ZL, Sun LJ, Li Y, Feng Q, Guo CY, Wang HF, Zhao PH, Liu Y, et al: Identification and characterization of epitopes from influenza A virus hemagglutinin that induce broadly cross-reactive antibodies. Int J Mol Med 3: 1673-1682, 2018.

32. Gong X, Yin H, Shi YH, Guan SS, He XQ, Yang L, Yu YJ, Kuai ZY, Jiang CL, Kong W, et al: Conserved stem fragment from $\mathrm{H} 3$ influenza hemagglutinin elicits cross-clade neutralizing antibodies through stalk-targeted blocking of conformational change during membrane fusion. Immunol Lett 172: 11-20, 2016.

This work is licensed under a Creative Commons Attribution-NonCommercial-NoDerivatives 4.0 International (CC BY-NC-ND 4.0) License. 